\title{
EFFECT OF LAPAROTOMY ON LUNG VOLUME. DEMONSTRATION OF A NEW TYPE OF PULMONARY COLLAPSE
}

\author{
BY HENRY $K$. BEECHER 1 \\ (From the Surgical Services and Metabolism Laboratory of the Massachusetts \\ General Hospital, Boston)
}

(Received for publication February 20, 1933)

In a previous communication (1) it was shown that laparotomy produces characteristic changes in the function of respiration. These included marked reduction in tidal air, complemental air, supplemental air and in the vital capacity, together with increase in respiratory rate. No significant change occurred in minute volume.

The object of the present work was to carry this study further and, by adding the measurement of the residual air, to discover whether laparotomy causes any alteration in the actual volume of the lungs. It was hoped that such a study might throw light on the factors responsible for postoperative pulmonary complications.

- Terminology applied to the divisions of total lung volume is shown diagrammatically in Figure 1. In comparing the lung volume of one person with that of another or of the same person at different times it is obviously necessary to employ the same phase of respiration.

The measurement of the residual air, that is to say, the air remaining in the lungs at the end of a maximal expiration, can be measured even in sick patients, if cooperative, after operation by the method described below, and to the residual air thus determined may be added the vital capacity which gives the total or maximum lung volume. For the purpose of comparing the pulmonary volumes of patients before and after laparotomy, I have preferred, however, what I have called subtidal volume to all other volumes, partly because it does not require the degree of cooperation, possibly painful, necessary in residual air measurement and partly because for the reasons given below I look upon it as the most significant of all lung volumes.

\section{METHODS}

In measuring residual air and subtidal volume, I have used Christie's (2) method with slight modifications. This method measures the quantity

1 During the two years in which the bulk of this work was done the writer was the holder of the James Jackson Cabot Fellowship of Harvard University. This study and the one preceding it (1) were awarded the Warren Triennial Prize of the Massachusetts General Hospital for 1931. 


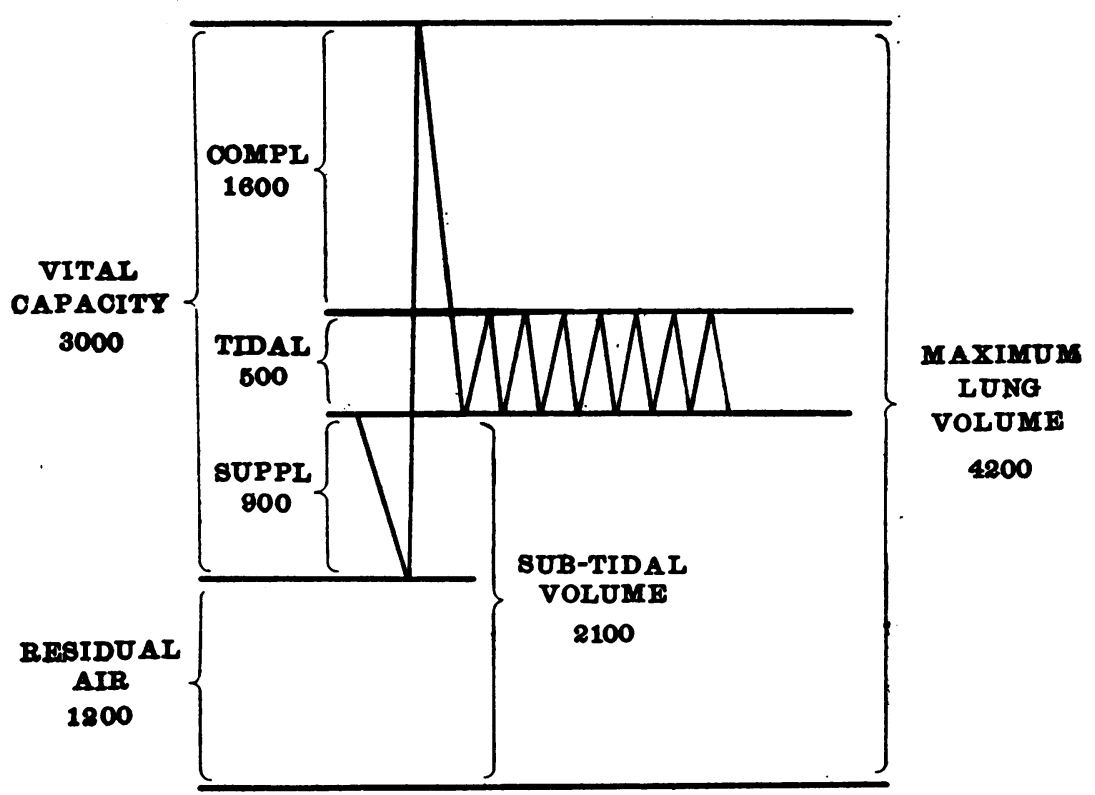

Fig. 1. Divisions of Lung Volume

Numbers represent cc.

of air in the lungs at the instant the patient's lungs and a spirometer become parts of a closed system. The nitrogen present in the lungs at the instant of connection is diluted with a known quantity of oxygen. The lung volume can be calculated from the degree of the dilution by reference to an equation which expresses the fact that the volume of nitrogen present in the closed system at the start will be unchanged at the end of the period of measurement, i.e.,

$$
x \frac{y}{100}+d \frac{79.1}{100}=(x+d+a) \frac{y}{100} .
$$

$x=$ lung volume in cc. at the instant the closed system was established. $d=$ dead space of the system.

$v=$ alveolar nitrogen at the start of the analysis.

$a=$ oxygen added minus the oxygen consumed during the period of measurement.

$y=$ nitrogen percentage found in the system at the end of the period.

Simplifying,

$$
x=\frac{(a+d) y-79.1 d}{v-y} .
$$

The volume of alveolar nitrogen, $v$, for a given individual at rest does not change. Since the aim was to show the effect of laparotomy on lung 
volume in a given individual, $v$ may be used as a constant, provided it is not affected by the operation. That the operation has no effect on the alveolar nitrogen will be shown below in the section on data.

Christie's apparatus consists of a spirometer of standard type, used in measuring the basal metabolic rate. He removes the soda lime scrubber from the body of the spirometer and fills that space with paraffin which is pierced by the inspiratory and expiratory tubes. The soda lime scrubber must then be inserted in the expiratory circuit outside of the spirometer. This requires considerable alteration of the machine and tends to make the apparatus more cumbersome, less adapted to ward use. I have found it possible to avoid this alteration and thus to use an apparatus which is more compact than that described by Christie: The unaltered twelve-inch Benedict-Roth ${ }^{2}$ metabolism spirometer met the requirements well, after the air trap around and beneath the soda lime container had been eliminated. Unless eliminated, this region contains a stagnant pool of air which does not come into equilibrium with that in the remainder of the circuit and will vitiate the results. The space beneath and around the sides of the soda lime scrubber was filled with paraffin. Before pouring in paraffin a small, stiff, rubber tube was connected with the oxygen tap. The tube extended to the top of the spirometer, being sealed in place by paraffin. Oxygen is added through this tube and samples for analysis removed by means of it.

A channel must be cut down through the paraffin wall to the outlet pipe of the spirometer. (The cross sectional area of this channel should be the same as that of the ventilation tube through which the patient breathes.) The inside of the closed system then contains a space, all parts of which are easily accessible to the diffusing gases, and pools of stagnant air are avoided, without the need of making Christie's extensive alterations of the spirometer. The apparatus remains compact.

\section{DATA}

That the alveolar nitrogen is not affected by laparotomy is indicated in Table I; $v$, it appears, may be used as a constant in the above equation.

Thirty-five patients were studied before and after operation. In men, there were 5 gastric operations, 1 appendectomy, 1 abdomino-perineal resection because of carcinoma of the rectum, 1 cecostomy, 2 lower abdominal exploratory laparotomies, and 7 hernia repairs. In women, there were 8 cholecystectomies, 2 gastric operations, 6 lower abdominal exploratory laparotomies, and 2 uterine operations.

Data were obtained as described in the preceding paper, one to three days before and then from day to day following operation, and the changes in the volumes were studied. All of the values obtained were corrected for the difference between the temperature of the air in the lungs and that in the spirometer. The gas volumes were reduced to standard conditions.

2 Warren Collins Co., Boston. 
TABLE I

Alveolar nitrogen

\begin{tabular}{|c|c|c|c|c|}
\hline Sex & Operation & $\begin{array}{l}\text { Days post- } \\
\text { operative }\end{array}$ & Alveolar $\mathrm{N}_{2}$ & $\begin{array}{l}\text { Variation } \\
\text { from average }\end{array}$ \\
\hline $\begin{array}{l}\mathbf{F} \\
\mathrm{F} \\
\mathbf{M} \\
\mathrm{M} \\
\mathrm{M} \\
\mathrm{F} \\
\mathrm{F} \\
\mathrm{M} \\
\mathrm{M}\end{array}$ & 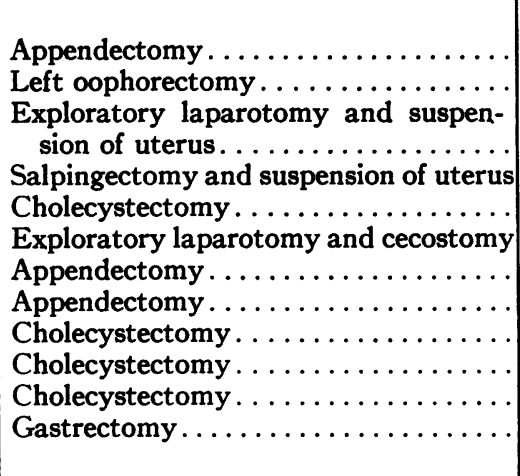 & $\begin{array}{l}5 \\
3 \\
2 \\
7 \\
7 \\
1 \\
3 \\
6 \\
0 \\
3 \\
7 \\
1\end{array}$ & $\begin{array}{l}\text { per cent } \\
79.87 \\
80.65 \\
\\
80.82 \\
79.84 \\
79.85 \\
80.63 \\
80.67 \\
79.78 \\
80.75 \\
79.72 \\
79.63 \\
80.62 \\
80.24 \text { Average }\end{array}$ & $\begin{array}{l}-0.37 \\
+0.41 \\
+0.58 \\
-0.40 \\
-0.39 \\
+0.39 \\
+0.43 \\
-0.46 \\
+0.51 \\
-0.52 \\
-0.61 \\
+0.38\end{array}$ \\
\hline
\end{tabular}

The standard error of the mean $S E_{M}=\left(\sqrt{\Sigma D^{2}} / N\right)$ is 0.13 .

The extremes here produce a variation in typical results less than 3 per centif used in place of the mean.

As in the preceding paper, the values secured before operation were arbitrarily called 100 per cent, and the postoperative ones, fractions of these. Because of the practical difficulties in the way of obtaining an adequate series of data following operation in each case, all of the values obtained, based on 696 measurements, were combined and are presented in Figure 2.

To prove that the changes shown in Figure 2 are not only apparent but significant, the standard errors before and after operation have been calculated for each curve. The difference between the averages of the actual values, not per cents, must be more than twice the standard error if they are to be regarded as having significance. The data on which the three curves from 35 patients are based are given in Table II.

From a study of Figure 2, it can be seen that the residual air has undergone on the fourth day a decrease of 13.2 per cent. The greatest decrease, 33.0 per cent, in the maximum lung volume occurs on the second day. On the first day, the subtidal lung volume was 16.0 per cent smaller than it was before operation, on the second day 18.2 per cent, on the fourth day 19.8 per cent; there has been an absolute decrease in the volume of the lungs. In the two weeks after operation, the lungs gradually regained their original volume. Of thirty-five cases studied from this point of view, 29 cases (82.9 per cent) showed a reduction greater than 10 per cent in subtidal air, and 6 cases a less. Of the 6 ( 17.1 per cent), 4 were in women, all of whom had undergone cholecystectomies; 2 were in men both of whom had undergone hernia repair. 


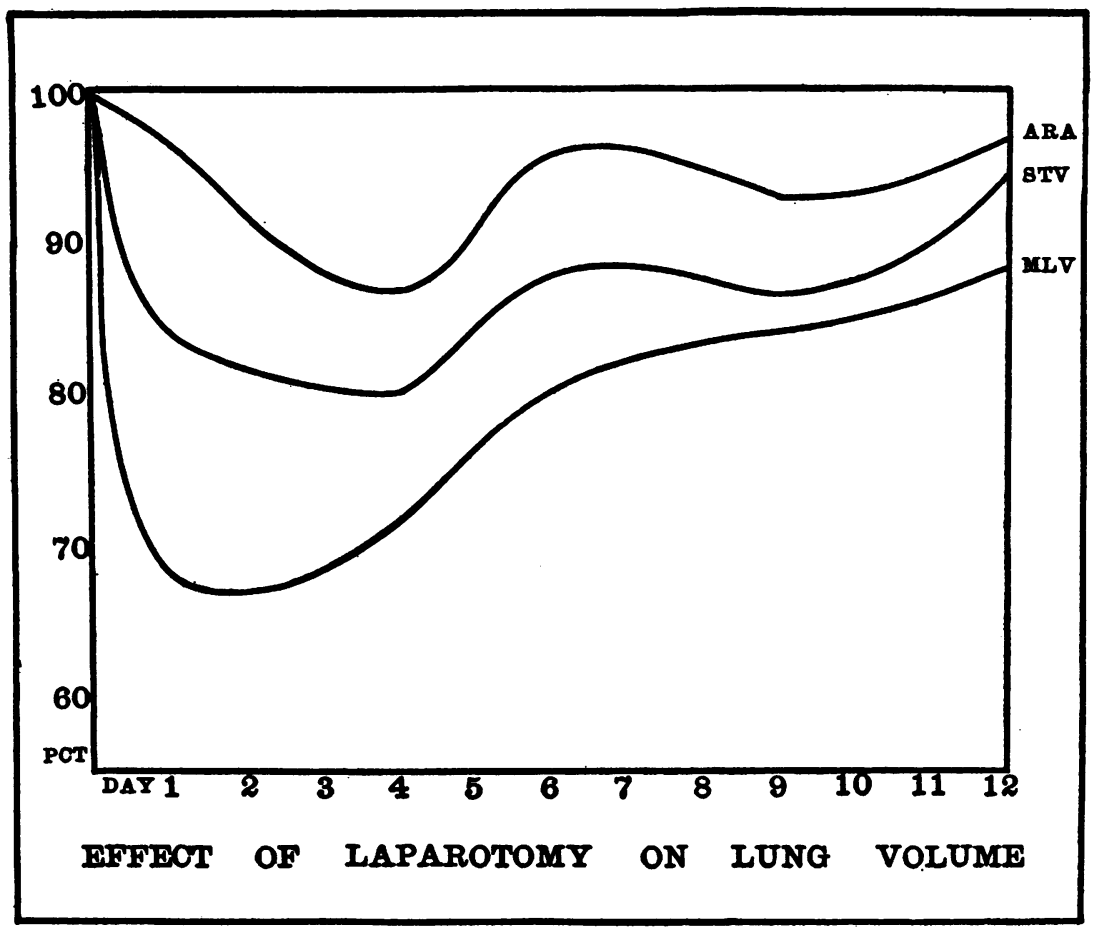

FIG. 2

$A R A=$ Absolute residual air

$S T V=$ Subtidal volume

$M L V=$ Maximum lung volume

Abscissa $=$ Days postoperative

Ordinate $=$ Postoperative per cent of preoperative values.

TABLE II

Changes in lung volumes

\begin{tabular}{|c|c|c|c|c|c|c|c|}
\hline \multirow[b]{2}{*}{ Curve } & \multicolumn{2}{|c|}{ A. Before operation } & \multicolumn{2}{|c|}{ B. After operation } & \multicolumn{2}{|c|}{$\begin{array}{c}\text { Differences between } \\
\mathrm{A} \text { and } \mathrm{B}\end{array}$} & \multirow[b]{2}{*}{ Change } \\
\hline & $\begin{array}{c}\text { Pre- } \\
\text { operative } \\
\text { average } \\
\text { volume } \\
\text { control }\end{array}$ & $\begin{array}{l}\text { Stand- } \\
\text { ard } \\
\text { error of } \\
\text { control }\end{array}$ & $\begin{array}{l}\text { Post- } \\
\text { operative } \\
\text { average } \\
\text { volume } \\
\text { contrast }\end{array}$ & $\begin{array}{l}\text { Stand- } \\
\text { ard } \\
\text { error of } \\
\text { con- } \\
\text { trast }\end{array}$ & $\begin{array}{c}\text { Difference } \\
\text { between } \\
\text { average } \\
\text { volume } \\
\text { control and } \\
\text { contrast }\end{array}$ & $\begin{array}{c}\text { Stand- } \\
\text { ard } \\
\text { error }\end{array}$ & \\
\hline $\begin{array}{l}\text { Residual air, } c c . . . . . . \\
\text { Maximum lung volume, }\end{array}$ & 2075 & 176.3 & 1106 & 191.8 & $969 \pm$ & 260.5 & Significant \\
\hline $\begin{array}{r}c c . . \ldots \ldots \\
\text { Subtidal volume, } c c . .\end{array}$ & $\begin{array}{l}5208 \\
2796\end{array}$ & $\begin{array}{l}396.0 \\
235.4\end{array}$ & $\begin{array}{l}3492 \\
2162\end{array}$ & $\begin{array}{l}238.0 \\
162.5\end{array}$ & $\begin{array}{r}1716 \pm \\
634 \pm\end{array}$ & $\begin{array}{l}462.0 \\
286.0\end{array}$ & $\begin{array}{l}\text { Significant } \\
\text { Significant }\end{array}$ \\
\hline
\end{tabular}


The relation of the postoperative decrease in vital capacity to the decrease in subtidal volume (Figure 3) was measured in the same patients. The effect on vital capacity is based on 739 measurements. (Before operation the standard error was 134.0 and on the second day, 82.5. The difference is $1380 \pm 157.3$, the standard error; the curve of vital capacity shows, therefore, a significant change following operation.)

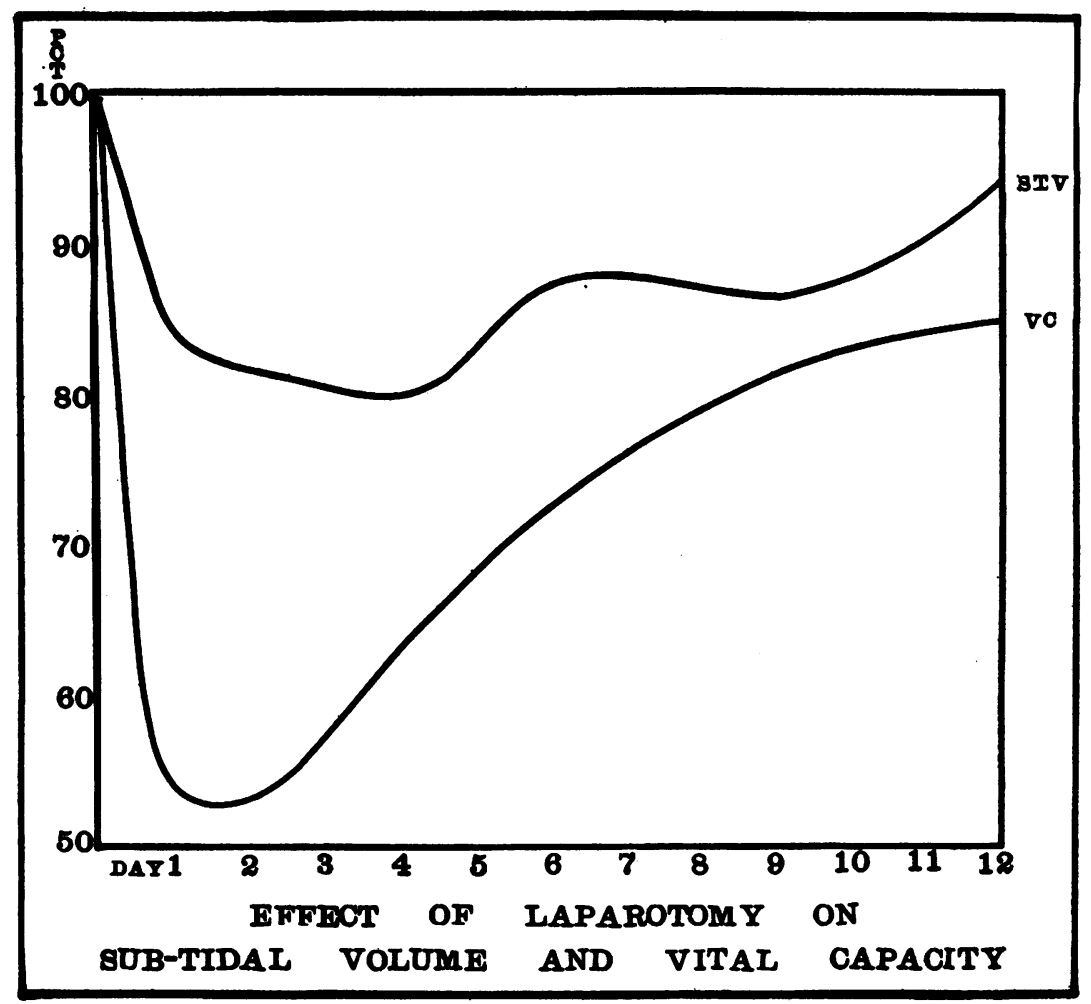

FIG. 3

$S T V=$ Subtidal volume $V C=$ Vital capacity

Abscissa $=$ Days postoperative

Ordinate $=$ Postoperative per cent of preoperative values.

\section{DISCUSSION}

The effect of laparotomy on lung volume at three phases of respiration is shown in Figure 2. Maximum lung volume requirès for its determination the measurement of vital capacity and is therefore not reliable as a measure of lung volume. This is evident when one considers how vital capacity is obtained. It is not possible to say that crippling of vital capacity after operation means anything more than injury to, or painful 
inhibition of, the respiratory mechanism. Residual air measurements in postoperative patients can be made with accuracy in the very cooperative patient; however, if such a patient expires only a fraction of that which he is able a false increase will be obtained when the volume of the residual air is calculated. The residual air may therefore appear to increase even though a small pulmonary collapse might have occurred.

There is a lung volume which can, on the other hand, be measured without requiring painful cooperation, which does not require any respiratory gymnastics, and which accurately reflects postoperative changes. This is the subtidal volume (Figures 1 and 2). When patients were too weak to seal the rubber mouthpiece with their lips, these were held tight for them. Occasionally patients slept during the procedure.

Measurement of the subtidal volume shows a consistent and significant decrease following laparotomy. This might be due merely to downward movement of the mid-position of tidal air or it might be due to decrease in the residual air from any cause. But this shrinkage cannot be due solely to this downward shift of mid-position because the decrease is actually as large as the entire volume of the supplemental air before operation. It is inconceivable that the postoperative, natural expiratory level could fall as low as the preoperative forced expiratory level. I believe that the results obtained must be interpreted, therefore, as signifying that some sort of actual pulmonary collapse has followed operation.

Several sorts of collapse are conceivable, for example, massive collapse of the whole lung, or atelectasis of smaller local areas of lung tissue may occur. There was no evidence of either of these on physical examination, and in six in which the examination was made, no evidence of them was found on x-ray photography. It is to be inferred that therefore the collapse observed was diffuse and partial, not local and complete; however, lobular total collapse may have occurred. This might be called collapse without symptoms; yet, since it occurred following 82.9 per cent of laparotomies, some of the "usual" postoperative manifestations may be due at least in part to its development, for example, the typical postoperative rise in pulse rate and the typical rapid and shallow respirations which were described in the preceding paper (1).

\section{SUMMARY AND CONCLUSIONS}

1. Christie's method for measuring residual air has been applied successfully to a clinical problem. It provides a means of studying the lungs of sick patients, and is superior to the measurement of the vital capacity.

2. Following laparotomy there is marked decrease in the lung volumes. The effect on residual air alone is quantitatively not significant. The same is true of maximum lung volume. The effect on subtidal volume is significant-it decreases one-fifth. Reasons are given for believing that this 
shrinkage is due to a type of diffuse, partial collapse of the lungs not heretofore demonstrated, rather than to local total collapse.

3. Crippling of the respiratory mechanics indicated by decrease of vital capacity precedes the development of this diffuse type of collapse.

The writer wishes to express his appreciation of the interest of Dr. James H. Means and Dr. Edward D. Churchill in this work, and to thank them for many valuable suggestions made during the course of it.

\section{BIBLIOGRAPHY}

1. Beecher, Henry K., J. Clin. Invest., 1933, xii, 639. The Measured Effect of Laparotomy on the Respiration.

2. Christie, R. V., J. Clin. Invest., 1932, xi, 1099. The Lung Volume and its Subdivisions. I. Methods of Measurements. 